\title{
A RACIONALIDADE DOS FORMATOS PRODUTIVOS AUTOGESTIONÁRIOS
}

\author{
Luiz Inácio Gaiger*
}

Resumo: O fenômeno atual da economia solidária reintroduziu o debate sobre as vantagens comparativas dos formatos coletivos de gestão e de organização do trabalho. Para contribuir com o tema, através da articulação entre a pesquisa empírica e a reflexão teórica, este trabalho analisa dados de uma investigação qualitativa sobre experiências de economia solidária, focalizando seus fatores dinâmicos também diacronicamente, por meio da comparação com resultados de pesquisas anteriores similares, realizadas anos atrás. Ao fazê-lo, considera parte da extensa bibliografia sobre os trunfos e desvantagens da autogestão e da cooperação em empreendimentos econômicos. A linha principal de argumentação desenvolvida reconhece o papel indispensável das motivações, da participação e da cooperação. Ao mesmo tempo, revê o conceito de eficiência, vindo a ressaltar a presença de uma racionalidade assente na comunidade de trabalho, fundada em circuitos de reciprocidade de conteúdo simbólico e projetivo, que passam a determinar os comportamentos e a diluir as fronteiras entre interesses individuais e coletivos.

Palavras-chave: economia solidária, trabalho cooperativo, racionalidade produtiva.

A economia solidária evoca um campo multiforme de iniciativas, paulatinamente abordado por estudos empíricos abrangentes (Singer; Souza, 2000; Gaiger, 2004) e por intentos de

\footnotetext{
* Doutor em Sociologia (Université Catholique de Louvain) e pesquisador do CNPq desde 1999. Dedica-se a estudos sobre os movimentos sociais e a economia solidária. Lidera o Grupo de Pesquisa em Economia Solidária (www.ecosol.org.br). Coordena a Cátedra da UNESCO "Trabalho e Sociedade Solidária", implantada na Universidade do Vale do Rio dos Sinos em junho de 2002. É professor e coordenador-executivo do Programa de PósGraduação em Ciências Sociais Aplicadas da Universidade.E-mail: gaiger@unisinos.br

Trabalho realizado com base em estudos do Grupo de Pesquisa em Economia Solidária, do Programa de Pós-Graduação em Ciências Sociais da Universidade do Vale do Rio dos Sinos (www.ecosol.org.br), com apoio do CNPq e da FAPERGS. Versão preliminar foi apresentada no XII Congresso Brasileiro de Sociologia, em 2005.
}

Artigo recebido em 21 dez. 2005; aprovado em 28 mar. 2006. 
sistematização teórica (Cattani, 2003). Essas iniciativas, designadas de solidárias, assumem em dose variável um caráter coletivo na gestão, na posse dos meios de produção e no processo de trabalho, minimizando a presença de relações assalariadas e provocando o envolvimento com os problemas da comunidade e com as questões da cidadania. As experiências variam, porque são distintos os seus protagonistas, suas origens e motivações, suas atividades econômicas e, naturalmente, seus resultados. Sua expansão é observada em diversos continentes, ao sul e ao norte (Santos, 2002), bem como suas conexões com novos movimentos sociais (Mendell, 2003) e, por outro lado, suas fragilidades e incertezas (Lima, 2004). ${ }^{1}$

Embora o tema desperte crescente interesse, são ainda infreqüentes os estudos empíricos sistemáticos sobre as práticas de autogestão e cooperação introduzidas e vivenciadas por essas experiências. A falta de uma análise interna dos empreendimentos, do seu momento de gênese à sua evolução ulterior, dificulta a identificação dos fatores materiais, sociais e culturais que impulsionam os indivíduos a aderirem e, sobretudo, a permanecerem nessa empreitada. Com isso, as análises limitam-se a constatar aquelas circunstâncias que, à revelia e a contragosto desses trabalhadores, os compeliram a buscar alternativas de ocupação e renda, como se a existência dessas pressões fosse suficiente para conduzi-los, passivamente, numa determinada direção, para quase todos nova e incerta.

Em verdade, há tempos reitera-se a necessidade de superar a postura teórica que toma as determinações macroestruturais como fonte explicativa das luta sociais, de modo independente dos valores, das formas de sociabilidade e dos novos fatos gerados pelos próprios atores sociais em questão, como reação e, ao mesmo tempo, como conduta orientada por eles. Como assinalava Kowarick $(1988,18)$, situações de pauperização originária do processo produtivo, de espoliação urbana, de expropriação da terra, de opressão cotidiana, "nada mais são do que matérias-primas que potencialmente alimentam as reivindicações populares: entre estas e as lutas sociais propriamente ditas há todo um processo de produção 
de experiências, que não está de antemão tecido na teia das assim chamadas condições materiais objetivas".

Da mesma forma, não são incomuns trabalhos que, ao se debruçarem sobre os formatos cooperativos e autogestionários, concluem pela sua funcionalidade para o capital, sem darem maior atenção à necessidade de discernir o que neles pode ser efeito direto de externalidades infensas às soluções de gestão buscadas internamente - como as desigualdades estruturais do mercado -, daquilo que decorre das boas práticas participativas e autogestionárias ou, antes pelo contrário, da sua cabal inexistência, camuflada sob o rótulo cooperativo afixado pela empresa. Se os intentos produtivos genuínos são frágeis e susceptíveis de descaminhos, quando então se confundem com os casos de manipulação intencional, não se pode atribuir sem mais que isso é devido à natureza socializada e às práticas de autogestão desses empreendimentos, nem significa que estejam desprovidos de qualidades que representem uma condição de trabalho e de vida apreciável para os trabalhadores, diante de suas outras reais alternativas.

Ao penetrar nesse terreno, a exposição a seguir toma outra direção. Em síntese, articula os seguintes argumentos: a) a indivisão social entre o capital e o trabalho, peculiar aos empreendimentos de economia solidária, somada ao acionamento de circuitos relacionados à autogestão e ao trabalho cooperativo, configura-os como formas sociais de produção não-capitalistas, dotadas de fatores de eficiência singulares; b) essas formas de produção caracterizam-se pela presença de uma racionalidade assente na comunidade de trabalho, fundada em vínculos de reciprocidade, de forte conteúdo simbólico e projetivo, os quais passam a determinar os comportamentos e a diluir as fronteiras entre interesses individuais e coletivos; c) em face da sorte ordinariamente reservada aos trabalhadores, a experiência socioprodutiva nos empreendimentos de economia solidária propicia novos processos de subjetivação, com sentido emancipatório; d) todavia perduram obstáculos relevantes, derivados do contexto externo ou oriundos das novas contradições internas, vividas pelos empreendimentos solidários; e) esse fato fragiliza as suas conquistas, 
sujeitando-os a retrocessos e à necessidade de escolhas, que excluem certas possibilidades de desenvolvimento dos empreendimentos e de realização mais plena dos trabalhadores.

As duas principais pesquisas empíricas que embasam essa linha interpretativa tiveram por objeto um conjunto de experiências associativas de geração de trabalho e renda, levadas à frente por trabalhadores rurais e urbanos no Estado do Rio Grande do Sul, desde os anos 90. O objetivo de tais pesquisas foi revalidar e retificar as conclusões de estudos anteriores (Gaiger, 1994; 1996; Gaiger et al., 1999), a respeito da viabilidade daquelas iniciativas econômicas, isto é, das diversas condições e dos diferentes meios que, direta ou indiretamente, condicionam os empreendimentos solidários ou são por eles adotados, de modo a favorecer sua implantação, seu desenvolvimento e, principalmente, seu êxito como opções efetivas de vida econômica para os trabalhadores. Esse fatores foram avaliados principalmente quanto às características autogestionárias e às exigências de eficiência produtiva dos empreendimentos, aspectos em que poderiam estar instaurando uma racionalidade scioeconômica específica.

A pesquisa de campo mais recente, em 2003, propiciou uma nova coleta de dados junto aos mesmos empreendimentos investigados cinco anos antes, em 1998. As hipóteses então lançadas, sobre os fatores de entrave e de êxito daqueles empreendimentos, foram revisadas à luz da trajetória por eles percorrida e das novas condições em que se encontravam. No lugar de projetar, sobre a história dos emprendimentos, dados apurados em um único instantâneo do tempo, buscou-se cotejar dois momentos do percurso das experiências, a fim de estabelecer as suas linhas de evolução de forma mais segura e conclusiva. Além de visitas aos empreendimentos para coleta direta de informações e documentos, somadas a contatos com assessorias e organizações de apoio, o grupo de pesquisa procedeu à elaboração minuciosa de uma grade de indicadores, visando objetivar a avaliação de cada experiência e compará-las entre si e com os dados da pesquisa anterior, sob diferentes ângulos e critérios. ${ }^{2}$ 
Não obstante o estado geral de fragilidade que as caracteriza, essas experiências, em certas circunstâncias, logram consolidarse e atingir níveis de acumulação que as habilitam a um processo de crescimento sustentado. Para elucidar que fatores principais intervêm nessas situações, as pesquisas mencionadas focalizaram propositalmente experiências com razoável desempenho na tarefa de conciliar suas premissas ideológicas e organizacionais com sua viabilidade econômica a médio e longo prazos. De modo que o seu corpus empírico não representa a economia solidária em geral, mas o seu lado mais visivelmente alternativo e bem-sucedido. ${ }^{3}$ Com essa ressalva, os empreendimentos de economia solidária (EES $)^{4}$ foram escolhidos de modo a expressarem a diversidade econômica, institucional e regional da economia solidária no Estado, abarcando então diferentes categorias sociais e distintos tipos de atividade econômica (Tabela 1).

\section{Tabela 1 - Divisão dos empreendimentos por categorização econômica}

\begin{tabular}{|c|c|}
\hline Atividades & $\begin{array}{l}\mathrm{N}^{0} \text { de empreendimentos de economia } \\
\text { solidária }\end{array}$ \\
\hline Produção agrícola & $6 \quad(19 \%)$ \\
\hline Alimentação & $5 \quad(16 \%)$ \\
\hline Comercialização & $5 \quad(16 \%)$ \\
\hline Vestuário & $5 \quad(16 \%)$ \\
\hline Misto & $(9 \%)$ \\
\hline Triagem de resíduos sólidos & $(9 \%)$ \\
\hline Serviços gerais (ou de trabalho) & $(9 \%)$ \\
\hline Metalurgia & $(6 \%)$ \\
\hline Total & $32(100 \%)$ \\
\hline
\end{tabular}

A caracterização dos EES segundo as propriedades já citadas e outras, como a população envolvida, o contexto inicial e o regime jurídico, permitiu subdividi-los em segmentos: grupos de empreendimentos com características socioeconômicas e culturais similares, em tese explicativas da sua dinâmica e das suas 
possibilidades de desenvolvimento (Tabela 2). Em cada segmento, procurou-se observar traços particulares, do ponto de vista solidário e empreendedor. $\mathrm{O}$ exame das concomitâncias e repulsões entre os diferentes indicadores completou, no essencial, o percurso analítico executado.

Tabela 2 - Divisão dos empreendimentos por segmento

\begin{tabular}{|c|c|}
\hline Segmentos & $\begin{array}{l}\mathbf{N}^{0} \text { de empreendimentos de } \\
\text { economia solidária }\end{array}$ \\
\hline Pequena associação ou grupo familiar & $9 \quad(28 \%)$ \\
\hline Associação de pequenos produtores rurais & $7 \quad(22 \%)$ \\
\hline Coletivos de assentamentos rurais & $6 \quad(19 \%)$ \\
\hline Cooperativa de produção & $4(12,5 \%)$ \\
\hline Associação de triagem de resíduos & $3 \quad(9 \%)$ \\
\hline Cooperativas de trabalho & $(9 \%)$ \\
\hline Total & $32(100 \%)$ \\
\hline
\end{tabular}

Dada a natureza peculiar desse campo de iniciativas, por seu intento de lograr eficiência econômica sem perda do seu caráter solidário e autogestionário, não é possível aplicar sobre ele, dedutivamente, conclusões de estudos congêneres referidos a empreendimentos econômicos tradicionais. $\mathrm{O}$ fato de que tais empreendimentos adotem princípios de gestão democrática, de autogestão produtiva e de cooperação no trabalho, em absoluto, é secundário. ${ }^{5}$ Assim, as pesquisas empíricas, geradoras de dados primários, necessitam estar em compasso com esforços de teorização e de formulação de hipóteses apropriadas. O entendimento preliminar da questão, quando da pesquisa realizada em 2003, decorre das aquisições progressivamente trazidas pelos estudos precedentes (Gaiger, 1996, 2000, 2001): o diferencial decisivo de êxito dos empreendimentos repousa na sua capacidade de conciliar as relações de trabalho que lhe são próprias com os imperativos de eficiência, de modo a converter a própria cooperação em viga mestra de uma nova racionalidade. Nessas circunstâncias, os resultados passam a 
depender em larga medida das virtudes do trabalho consorciado, no interesse da sobrevivência do empreendimento e em favor dos próprios produtores. $\mathrm{O}$ solidarismo e a cooperação no trabalho, uma vez internalizados como prática cotidiana, propiciariam fatores adicionais de eficiência, em prol do empreendimento.

Sob pena de um raciocínio tautológico, a questão é demonstrar como esse círculo virtuoso se estabelece e por quais mecanismos se reproduz. Além disso, se o trabalho cooperativo representa, além de uma opção ética, uma alavanca singular para o êxito econômico dos empreendimentos solidários, resta verificar se esse diferencial é sólido o bastante para livrá-los do padrão de instabilidade e insolvência que assola os pequenos negócios. Apenas estudos dirigidos à evolução dessas experiências ao longo do tempo poderiam atestar seu desempenho, ao distinguirem as suas forças básicas de sustentação de outras circunstâncias, contingentes e efêmeras. As considerações feitas a seguir, em certo sentido são uma volta ao tema: elas se valem das novas contribuições da pesquisa de 2003, cujo maior refinamento no plano metodológico permitiu avanços apreciáveis na identificação dos dinamismos internos e das novas contradições que caracterizam os empreendimentos; ao mesmo tempo, elas agregam novos elementos em favor da tese anterior, de uma simbiose possível entre solidarismo e empreendedorismo econômico. Antes de examinar essas novas aquisições, convém ter em vista o significado do trabalho e das relações sociais de produção assumidas pelos empreendimentos solidários.

\section{A ambígua centralidade do trabalho}

O trabalho ocupa uma posição central nos empreendimentos econômicos solidários, principalmente por duas razões. Em primeiro lugar, o trabalho é a razão de ser dessas iniciativas, que nascem para garantir uma atividade produtiva a seus integrantes e protegê-los da desocupação. Manter os postos de trabalho passa naturalmente a ser a prioridade maior do empreendimento, mesmo ao preço de 
menores ganhos individuais, por ser ele obra dos trabalhadores, seu meio comum de subsistência, e porque isso significa preservar a capacidade produtiva do grupo. A necessidade de manter as pessoas ocupadas e respeitar as suas expectativas impõe restrições, pois obriga a descartar alternativas que seriam normais em empresas privadas, como eliminar postos de trabalho em tempos de crise, elevar os padrões mínimos de produtividade ou escalonar os níveis salariais, a fim de estimular a competição entre os trabalhadores. Ao mesmo tempo, garantir trabalho para todos torna necessário e razoável, portanto, objetivamente e subjetivamente lógico, adotar ou preservar um certo conjunto de medidas que fundamentam a política de gestão e de desenvolvimento do empreendimento. Em suma, o fator trabalho é um elemento intrínseco que confere características específicas aos empreendimentos.

Em segundo lugar, o trabalho é o principal ou virtualmente o único recurso propulsor daquelas atividades econômicas, devido essencialmente à fraca e geralmente insuficiente presença de capital e demais fatores produtivos. Na pesquisa de 1998, sobressaiu o fato de os EES utilizarem o trabalho intensivamente, compensando a baixa capacidade de investimentos e buscando esgotar, nas dimensões do empreendimento, suas possibilidades de atendimento ao mercado. Havendo demanda, a jornada de trabalho ultrapassa largamente as oito horas diárias, ou absorve o tempo ocioso deixado pela ocupação principal.

O fato confirmou-se cinco anos depois. Numa cooperativa de confecções, a costura é realizada por agricultoras em jornadas extras, nas horas não ocupadas pelas lides agrícolas. Entre as cooperativas industriais, a produção coletiva é claramente prioritária, quando não excludente de outras ocupações: numa cooperativa metalúrgica, a insuficiência de equipamentos obriga os cooperados a alternaremse em turnos diurnos e noturnos, estando a produção futura de vários meses já comprometida no mercado; noutra cooperativa de vestuário, as novas instalações adquiridas na Incubadora Municipal serviram para reorganizar o processo produtivo, aumentar o volume de produção e incorporar novos setores, como a serigrafia e a 
alimentação. Noutro segmento, uma da associações de reciclagem mantém como premissa processar toda a matéria-prima recebida; disto continua dependendo a jornada de trabalho e o rodízio nas tarefas, mediante controle da pontualidade e monitoramento do ritmo de trabalho. Num dos empreendimentos do ramo de alimentação, as jornadas de trabalho permanecem em três turnos, exigindo dedicação integral ao EES, para garantir o abastecimento dos pontos de venda e um volume de produção que assegure auto-suficiência e investimentos progressivos. ${ }^{6}$

De um modo geral, a tendência observada de diversificar as linhas de produção e de atuação econômica insere-se nesse princípio, de melhor utilização do trabalho e do potencial produtivo que o EES representa, para lograr uma gradativa e difícil acumulação de capital, a partir das suas modestas bases materiais. Por serem empresas em que os ganhos individuais variam com a performance global, fundadas ademais em convicções e senso de responsabilidade, é compreensível que os trabalhadores disponham-se a um esforço maior, em busca dos resultados. Nesses casos, o caráter participativo e autogestionário dos empreendimentos parece sedimentar um padrão de comportamento - uma expectativa de cada um em relação aos demais e um compromisso frente a si próprio - marcado pela colaboração, pelo zelo e pela disponibilidade. Ao saberem que o mister de produzir não é "conversa de patrão" e que o ganho de cada um e o futuro de todos dependem do faturamento final, as condutas de absenteísmo ou negligência ficam limitadas a casos excepcionais, sem demora coibidos.

A centralidade do trabalho nos empreendimentos solidários reveste-se de uma natureza contraditória. Regra geral, os setores de atividade em que se situam os empreendimentos são demandantes de força-de-trabalho minimamente qualificada, ou cuja mecanização seria contraproducente. Exemplificam-no as cooperativas de serviços, mas também aquelas de calçados e boa parte da produção agrícola. Trata-se de ofícios pouco especializados, por conseguinte desvalorizados, que incorporam baixos níveis de conhecimento e maior emprego da força física, em atividades 
braçais ou de operação de instrumentos relativamente rudimentares, de baixa produtividade, ao não multiplicarem consideravelmente a força física neles aplicada. O fator trabalho vê-se reduzido à capacidade física somada dos trabalhadores. É apenas parcialmente diferente a situação dos empreendimentos que apostam na tradição artesanal de seus produtos, como os artigos coloniais ou ecológicos. De 1998 a 2003, esse aspecto não mudou: cabe ao trabalho - podese dizer, laborioso - agregar valor aos bens e serviços oferecidos. $\mathrm{O}$ fato tem uma implicação importante para nossa análise, à medida que deixa um papel preponderante à organização social dos empreendimentos, isto é, à eficiência alcançada pelo conjunto de trabalhadores através de relações de cooperação. ${ }^{7}$

Por outro lado, coincidindo com ampla literatura (cf. Espinoza; Zimbalist, 1984), o modo como nos EES se organiza e se vivencia o trabalho proporciona uma série de satisfações adicionais, além da renda e dos benefícios econômicos indiretos. Em diversos depoimentos, é enaltecida a experiência de ser sócio-trabalhador, em pé de igualdade com os demais, ao mesmo tempo que sócioproprietário, gestor do negócio, com direito a voz e voto, para definir os rumos do empreendimento. Da mesma forma, é valorizada a vivência do trabalho como algo edificante, como oportunidade de enriquecimento pessoal. O lado gratificante do trabalho neutralizaria consideravelmente sua face penosa, dotando a atividade produtiva de um sentido moral e simbólico elevado: participar de um empreendimento associativo e cooperativo significa colocar em prática os princípios de eqüidade, justiça e democracia; significa contribuir com a sociedade por meio de bens e serviços honestos e idôneos; significa demonstrar a importância do trabalhador e colaborar para o seu reconhecimento social.

Atividade onipresente, o trabalho constitui uma experiência de dupla face: como base da identidade do grupo, valorizado ao desenvolver seu potencial de satisfação e suas virtudes desalienantes e emancipatórias; como um dispêndio árduo e permanente, refletindo a carência de outros fatores de produção, por sua vez decorrente da baixa capacidade de acumulação, ponto nevrálgico das iniciativas 
de economia solidária. Diante desse quadro, é justo indagar se o trabalho organizado de forma autogestionária e cooperativa contém forças vitais internas que confiram rentabilidade suficiente para a sobrevivência e a consolidação dos empreendimentos, no presente contexto altamente seletivo da economia. Dizendo de outro modo, uma vez que os EES em estudo são precisamente aqueles que estão sobrevivendo, cabe questionar em que circunstâncias a cooperação e a eficiência produtiva desenvolvem-se conjuntamente e fazem do trabalho um elemento não apenas central, mas diferencial, equiparando ou dando aos empreendimentos associativos vantagens comparativas diante de seus concorrentes, em produtividade e competitividade.

Considerando as outras alternativas de ocupação e emprego realmente acessíveis aos trabalhadores da economia solidária, estar num empreendimento econômico solidário representa provavelmente um patamar socialmente superior, minimamente protegido dos riscos de desocupação, flexibilização e precarização do trabalho. ${ }^{8}$ Permanece contudo a questão da sua produtividade relativa, imprescindível para que a economia solidária suplante apreciavelmente o grau de instabilidade e insolvência dos pequenos empreendimentos. Os dados empíricos a respeito, colhidos na pesquisa empírica realizada em 2003, como veremos adiante confirmam as conclusões anteriores e acrescentam novos elementos sobre as situações em que as virtudes do trabalho cooperativo mais se manifestam e melhor contribuem para a longevidade dos empreendimentos.

\section{A indivisão entre capital e trabalho como nova totalidade}

Desde as mais remotas épocas, a vida econômica preponderou como uma atividade coletiva, voluntária ou compulsória. Em seus dois séculos, o capitalismo disseminou a cooperação e a conduziu a uma esfera muito mais ampla, ao dividir um mesmo processo de produção entre inúmeros trabalhadores, a fim de viabilizar a produção em larga escala, para mercados em contínua expansão. Organizar 
a cooperação em grandes contingentes foi uma necessidade até há pouco incessante, para operar e acompanhar o ritmo de máquinas cada vez mais possantes, ou para suprir sua falta em algumas etapas do processo produtivo. Em tempos mais recentes, quando as novas tecnologias mecanizaram integralmente o processo produtivo, dispensando parcelas daqueles contingentes, passa a ser requerido do trabalhador, no comando das máquinas, elevado senso de coordenação e grande espírito cooperativo (Leite, 1993; Rosenfield, 2004). Contudo, por mais sofisticadas que sejam as estratégias patronais para que os trabalhadores doem-se e colaborem com a empresa, o grau de ingerência que lhes é autorizado no processo produtivo, no sentido de aprimorar a cooperação técnica entre indivíduos e setores, segue contido pela divisão social objetiva do trabalho, característica da empresa capitalista, que estabelece prerrogativas muito distintas aos trabalhadores e aos representantes do capital. Direitos e deveres de uns e outros são distintos, em geral de sinais contrários.

Como tal, essa barreira objetiva é vencida pelos empreendimentos solidários. Entre os 32 EES pesquisados, observou-se a existência de formas de propriedade coletiva dos principais meios de produção em $75 \%$ dos casos; a presença de modalidades de trabalho coletivo em $94 \%$ dos casos, de modo predominante ou pleno em $69 \%$ deles. Nesses últimos, o patrimônio da empresa e boa parte dos meios de produção pertencem solidariamente aos trabalhadores e são postos a serviço do empreendimento. ${ }^{9}$ Por outro lado, algumas práticas de gestão participativa foram identificadas como preponderantes, a exemplo da tomada de decisões fundamentais pelo conjunto de associados ( $87 \%$ dos casos, em $72 \%$ de modo sistemático), do elevado comparecimento nas instâncias deliberativas e consultivas (87\%) e da divulgação de informações entre os membros do empreendimento (78\%). Esse conjunto de práticas, exercidas por indivíduos em posição estruturalmente similar diante do capital do empreendimento, age no sentido de eliminar a divisão social entre trabalhadores, gestionários e proprietários. Capital e trabalho encontram-se vinculados às mesmas pessoas - os trabalhadores associados - no plano material, pela socialização dos recursos produtivos; no plano político, pelos mecanismos de autogestão. 
Os indivíduos que geram o excedente, no âmbito da produção, simultaneamente são aqueles que deliberam sobre a finalidade e o uso do excedente produzido. Essa indivisão entre capital e trabalho não representa apenas uma diferença fundamental diante da produção capitalista; ao mesmo tempo, coloca os trabalhadores associados diante de uma dupla dialética: ${ }^{10}$ em primeiro lugar, distinguir e compatibilizar as necessidade de acumulação e de investimento do empreendimento (isto é, do capital), com as necessidades e interesses dos seus associados (isto é, do trabalho), que pressionam por ganhos imediatos, via antecipação ou maior divisão das sobras, etc. Questão do equilíbrio, geralmente tênue, entre preservar e distribuir os excedentes. Em segundo lugar, canalizar para o empreendimento os ganhos gerados pelos esforços do conjunto de trabalhadores, tornando tais ganhos essencialmente coletivos, e, ao mesmo tempo, reconhecer as diferenças entre os aportes individuais, fazendo-lhes jus através de contrapartidas proporcionais. Questão do equilíbrio entre os ganhos coletivos e os benefícios exlusivamente individuais.

$\mathrm{O}$ equacionamento dessas questões demanda que os trabalhadores tenham uma compreensão de sua experiência e do seu projeto pessoal intimamente vinculada ao coletivo, com o qual se identificam e no qual refazem a sua identidade. Sem essa dimensão identitária, o empreendimento não alcança a viabilidade social que lhe permitiria transpor suas fragilidades econômicas (Nunes, 2001, p. 144). ${ }^{11}$ Nas soluções buscadas, parece introduzir-se um princípio racionalmente consistente com o preceito de eqüidade que governa as relações entre os membros dos empreendimentos: evitar que existam indivíduos cuja sorte material melhoraria se a propriedade coletiva dos meios de produção ou outras medidas igualitárias fossem adotadas em mais alto grau para todos, pois então tais indivíduos estariam sendo vítimas de um dispositivo oculto de exploração. ${ }^{12}$

A presença de escolhas éticas indica que os trabalhadores associados, ao superarem a divisão entre o capital e o trabalho, ingressam não apenas em uma nova etapa de sua vida econômica, mas em uma nova totalidade, marcada por vínculos indissolúveis 
entre valores, relações econômicas e relações sociais. A mudança é mais ampla do que a substituição das relações assalariadas pelos vínculos cooperativos faz supor: modificam-se os princípios e os fins da organização econômica, alteram-se ao mesmo tempo as relações que os indivíduos contraem entre si, no que tange aos meios de produção, ao processo de trabalho e aos seus resultados. Uma nova racionalidade, positivamente desprovida da apropriação privada do excedente, passaria a presidir o agenciamento dos fatores produtivos. Ao mesmo tempo, para subsistirem como tais, os empreendimentos solidários necessitam dar conta de novas contradições.

Um modo inconfesso de enfrentá-las consiste em renunciar à nova forma social assumida pelo empreendimento solidário, deixando-o refluir paulatinamente até converter-se numa das expressões típicas da economia popularounalgum intento de feições empresariais. Esse caminho regressivo atingiu alguns empreendimentos de pequeno porte, dando-lhes feições familiares ou microempresariais, ao lado de cooperativas industriais em que a distância entre a direção e o chão da fábrica voltou a aparecer, esvaziando o seu conteúdo autogestionário. A outra alternativa, acionada pela maior parte dos empreendimentos em estudo, consistiu em valer-se tanto quanto possível dos novos recursos propiciados pela forma social de produção interna aos empreendimentos solidários. Pedalando, $o$ ciclista não cai: apostando no que lhes é peculiar, em especial no tocante à autogestão e às relações de trabalho, os empreendimentos geram forças produtivas singulares, logram manter-se à tona, ou mesmo prosperam. Essa linha de entendimento ganha contornos mais nítidos com os dados empíricos apurados em 2003.

\section{Os fatores de eficiência do trabalho cooperativo}

Os efeitos positivos do ambiente participativo e democrático, entre eles o maior zelo e compromisso com a eficiência, têm sido sublinhados pela literatura especializada (Carpi, 1997; Defourny, 1988), com base em situações similares às verificadas em nossos empreendimentos. Certos estudos (Espinoza; Zimbalist, 1984; 
Ponte Jr., 2000) ressaltam que a existência de práticas democráticas de gestão traz benefícios importantes do ponto de vista da confiança mútua e da motivação para o trabalho. Contrariamente aos modernos modelos de gestão das empresas capitalistas, apoiados em maior comprometimento do trabalhador, a autogestão confere à base social da empresa o poder de opinar e decidir igualmente em questões gerais e estratégicas. Nesses termos, a gestão coletiva facilita o consenso, empresta legitimidade às decisões e gera maior nível de adesão às estratégias adotadas. A participação, em igualdade de condições, faz circular o poder e impede que se recriem estamentos, incluindo-se aqueles derivados da organização técnica do trabalho, cujas tendências a introduzir uma nova divisão social do trabalho são sempre um risco latente.

Naturalmente, há fragilidades em alguns EES, como é o caso das cooperativas de trabalho, onde as atividades são mais individualizadas e os vínculos de caráter contratual, com envolvimentos recíprocos permanentes mais limitados. A gestão convertese na arte de fazer arranjos constantes entre interesses particulares momentâneos, sobretudo quando a cooperativa representa uma opção de trabalho complementar ou passageira para o associado. ${ }^{13}$ De modo mais geral, no conjunto dos EES, perduram algumas vezes diferenças na distribuição do poder político, quando se revelam inabituais a renovação dos quadros diretivos, o voto secreto em decisões fundamentais e a atuação de órgãos fiscalizadores independentes, ao que se soma ainda um menor envolvimento dos associados na gestão cotidiana do emprendimento e do trabalho.

Essas debilidades denotam a escassa presença de um fator de êxito considerado importante na pesquisa de 1998, referente à similitude de interesses e de dedicação ao EES por parte dos membros (Gaiger et al., 1999, p. 37). Quando a maior parte deles atribui um alto grau de importância à empresa coletiva, mesmo por razões pessoais, o empenho e o enfrentamento de riscos tendem a ser uniformes, o que evita desequilíbrios entre os aportes individuais e dispensa a existência de diferentes tipos de sócios ou participantes. Esse é o caso típico das cooperativas de produção e em assentamentos 
rurais, baseadas na socialização integral dos meios de produção e em processos coletivos de trabalho, sendo ademais empreendimentos que assumem um caráter essencial e dificilmente reversível para os associados. Mas pode ser igualmente o caso de iniciativas menores, que exemplificam as virtudes de pequenas empresas em que todos os sócios são proprietários e detêm direitos econômicos similares, ou mesmo de empreendimentos semifamiliares, cujo crescimento ao longo dos anos veio reforçar as expectativas e gerar maior adesão dos poucos associados.

Na mão oposta, onde as condições objetivas de partida entre os sócios eram desiguais, observa-se agora que terminou predominando o caminho do aprofundamento das diferenças, de concentração do patrimônio e do poder de decisão, dando lugar a empresas ordinárias, muito embora preservem práticas de solidariedade e de atenção à comunidade. Assim, um empreendimento rural recuou em suas atividades, restringindo-as a uma linha de produção, e concentrou o trabalho diário em apenas uma família, a única a depender ainda do empreendimento para a sua sobrevivência. $\mathrm{O}$ desequilíbrio de interesses e necessidades transformou a iniciativa num empreendimento familiar. Noutro caso, perdura uma inegável diferença de aporte em trabalho, de interesses e de implicação na gestão do empreendimento, entre o grupo da sede e os grupos rurais de costura, o que parece frear o seu desenvolvimento: as diretoras desejariam maiores resultados; as demais sócias, estando alheias à gestão cotidiana, mesmo concordando inclinam-se à passividade quanto à formulação de estratégias e outras decisões importantes.

O exame específico dos indicadores mais relacionados ao fator em análise indica uma nítida relação entre a sua presença e o melhor desempenho geral dos EES. Os dois indicadores mais importantes, para avaliar o nível de interesse e de dedicação dos membros dos EES (A12 - aporte em trabalho e capital similar entre os sócios, e A13 - envolvimento dos membros na gestão cotidiana do trabalho $e$ do empreendimento), atingem um escore alto (90 e 85\%) entre os 10 EES com melhor desempenho global, aparecendo tenuamente nas práticas dos 10 EES de menor desempenho. A existência de 
interesses e de quotas de participação semelhantes é típica dos EES mais bem-sucedidos. Num exame mais acurado, tomando-se ainda os 10 EES globalmente mais bem-sucedidos, percebe-se que o seu desempenho globalmente superior deve-se em boa medida à preservação das condições e práticas acima referidas, assim como a aspectos afins, como a restrição das atividades-fim tão-somente aos sócios e a admissão de trabalhadores não associados apenas excepcionalmente.

Num plano mais cirscunscrito, a autogestão aplicada ao processo produtivo, em espaços participativos de análise e deliberação quanto às linhas e metas de produção e à organização do trabalho, exerce efeitos positivos, propiciando que a criatividade dos trabalhadores se manifeste, explore competências adormecidas e confira ao trabalho um sentido positivo e estimulante. Um ambiente de trabalho participativo facilita a comunicação e favorece a identificação das porosidades do processo produtivo e de outras causas de ineficiência. O conhecimento tácito do trabalhador, no lugar de ser resguardado subjetivamente, para servir como arma de resistência contra o processo de objetivação do trabalho, passa a ser compartilhado, como parte do empenho de cada um em colaborar para a resolução de problemas. Ademais, estando legitimada pelo consentimento da maioria, a cooperação produtiva favorece a polivalência e a flexibilidade no trabalho, conforme as flutuações da demanda e outras necessidades circunstanciais. ${ }^{14}$

Como o trabalho de cada um passa a depender de escolhas feitas em conjunto, a autogestão nesse plano aumenta as chances de maior implicação pessoal na gestão do empreendimento como um todo. Nesse caso, abster-se de participar, renunciando à possibilidade de influenciar as decisões, somente para evitar os custos inerentes à participação, torna-se menos atrativo e traz o risco de desaprovação e censura. Por sua vez, a participação interfere nos parâmetros de gestão, ao introduzir continuamente questões de valor, referentes à justiça e à igualdade, em decisões tais como arbitrar o aporte em trabalho esperado de cada um e a contrapartida que lhe é devida. Portanto, da natureza coletiva dos processos de decisão emanam 
orientações intersubjetivas de conteúdo ético, como o preceito de justiça, tão elementar quanto comumente desprezado, segundo o qual, ao produzir determinada riqueza por sua atividade laboral, cada trabalhador é legítimo merecedor de digna recompensa, o que equivale, em outros termos, a eliminar a injusta exploração, tanto quanto seja possível aplicar e generalizar tal regra (Arnsperger; Van Parijs, 2000, p. 50).

De acordo com a pesquisa de 1998, os efeitos positivos do trabalho cooperativo são reforçados quando ocorre a incorporação de saberes profissionais especializados e sua transferência interna para os demais membros do grupo (Gaiger et al., 1999, p. 39). Assim, a divisão técnica do trabalho não cristaliza as diferenças de saberes e de competências iniciais, o que viria a resultar em concentração de poder e em discriminações. Em certos casos, reavaliados em 2003, ocorreu um retrocesso na socialização do conhecimento, paralelamente a um desequilíbrio gradativo na participação dos sócios-trabalhadores e a uma diminuição das frentes de produção. Todavia, a maior parte dos EES bem-sucedidos manteve essa preocupação, com iniciativas concretas.

Uma cooperativa de assentados manteve contínua assessoria técnica e cursos de contabilidade para os associados; no segmento da reciclagem, para superar a baixa escolaridade dos associados, firmou-se um convênio com várias entidades públicas, no âmbito do chamado "Projeto Galpão", que oferece escolarização para todos os catadores que não possuem ensino fundamental básico, entre os membros do empreendimento beneficiado, não se registraram casos de evasão; numa cooperativa de calçados, todos os associados trabalham na produção, inclusive o coordenador, que funciona como curinga, substituindo os demais quando necessário, e cada associado tem sua função na linha de produção, executando tarefas normalmente simples e sempre cadenciadas, intercaladas com dias de revezamento das funções, a fim de aprender todo o processo de produção ou evitar lesões causadas pelo esforço repetitivo; uma cooperativa de trabalho de grande porte, após haver reduzido sua área de atuação e diminuído o quadro de sócios, adotou uma 
estratégia de capacitação múltipla: treinamento doutrinário, sobre os princípios do cooperativismo; treinamento técnico, para o trabalho; e treinamento meio (psicológico e sociológico), orientado à mudança para a cultura do associativismo e do trabalho autônomo.

Os indicadores relacionados à incorporação de novos saberes (V13 - processos de qualificação da força-de-trabalho; V15 - ações de educação dos associados) foram observados parcialmente nos EES, indicando a existência de um flanco nesse quesito, por falta de maior investimento ou de chances de capacitação e formação da base social dos empreendimentos. Contudo, referendando sua importância, as ações educativas direcionadas aos sócios são nitidamente mais freqüentes $(80 \%)$ nos EES mais bem posicionados, do ponto de vista do desempenho global, e relativamente escassas (20\%) entre os EES menos bem posicionados. Quanto à socialização interna de saberes, é possível inferir sua maior ou menor influência com base na existência de práticas como a adoção de processos coletivos de trabalho ou de rotatividade de funções e tarefas no trabalho. Como já apontado, predominam nos EES processos de trabalho executados coletivamente, sobretudo entre os empreendimentos de melhor desempenho, que os adotam amplamente no âmbito da sua principal atividade econômica. Todavia, a alternância de tarefas, que poderia engendrar uma circulação de experiências e saberes, não se verifica como prática corrente, estando ao que se presume condicionada pelos formatos produtivos e pelos requisitos de competência indispensáveis a cada função, nos marcos da divisão técnica do trabalho típica do setor produtivo correspondente. Nesse aspecto, os EES menos inovam e mais adaptam-se às circunstâncias.

Outro fator de consistência dos EES, no tocante à gestão do processo produtivo, é o fato de remunerarem o trabalho com base em critérios intrínsecos, tais como o tempo dispendido e o grau de competência ou de responsabilidade envolvido nas tarefas (Gaiger et al., 1999, p. 40). Significa retirar o trabalho agregado pelo empreendimento da condição de valor subsidiário, dependente dos demais custos (geralmente, sob forma de um percentual) ou formado mediante o recurso sistemático de comprimir a retribuição aos 
trabalhadores, com o objetivo de oferecer preços competitivos. ${ }^{15} \mathrm{Na}$ história dos empreendimentos no Estado, empresas autogestionárias e cooperativas com estruturas mais complexas e maior grau de profissionalização, após haverem apostado num sistema indiferenciado de repartição dos ganhos, perceberam que isso simplesmente ignorava os desníveis de qualidade e de valor-agregado do trabalho, além de suprimir as diferenças de desempenho. Passaram então a um sistema mitigado, de remuneração proporcional às horas prestadas e ao grau de responsabilidade assumido. O problema é antigo (Gaiger, 1994), mas aos poucos vem sendo contornado: onde as tarefas são similares, predomina o pagamento pré-fixado, por hora trabalhada ou peça produzida; quando entram em jogo a qualificação profissional e o seu valor de mercado, a questão adquire contornos mais delicados. A tendência geral, confirmada na última pesquisa, é aproximar as faixas de remuneração, em observância do princípio da eqüidade, sem cair num igualitarismo pleno, que poderia desestimular o esforço e o aprimoramento pessoal.

Essa prática (aferida pelo indicador E14 - remuneração do trabalho diferenciada dos demais custos) tornou-se moeda corrente e predomina em todos os segmentos e tipos de EES, embora com nuances e modalidades específicas, de acordo com a atividade econômica em questão. Dois casos o ilustram com detalhe: em meio a um processo de reestruturação econômico-financeira, uma cooperativa metalúrgica aprovou em assembléia um plano de encargos e proventos com estímulos à participação e à formação socioprofissional dos associados. ${ }^{16}$ Numa cooperativa de produção agropecuária vinculada ao MST, a remuneração tem como índice a receita por hora auferida pelo setor leiteiro, por ser uma receita estável, vinculada à produtividade. As metas de aumento da produtividade propiciariam uma renda monetária líquida mensal de dois salários mínimos.

\section{Comunidade de trabalho e racionalidade produtiva}

Um último fator de êxito relacionado à organização do trabalho nos empreendimentos, identificado em ambas as pesquisas, diz 
respeito à sua vivência como uma atividade gratificante e estimulante (Gaiger et al., 1999, p. 32). Nos pequenos empreendimentos, os vínculos familiares e de amizade conferem uma marca lúdica ao trabalho, misto de atividade produtiva, convivência familiar e reunião de amigos. Numa das associações de reciclagem, há atividades de lazer, como churrascos, uma banda de RAP, um time de futebol e a Televisão Cata-cata, um grupo de teatro composto pelos associados que profere palestras sobre a importância dos cuidados com o lixo para a preservação do meio ambiente. Regra geral, observam-se práticas novas de integração social e cultural, com maior convívio entre os associados. Alguns empreendimentos melhoraram nesse aspecto, com o abrandamento de conflitos antes registrados. Embora não se tenha suficiente informação em vários casos, em nenhum deles ficou demonstrada a inexistência de aspectos de gratificação e motivação no trabalho: a grande maioria dos EES de melhor desempenho contemplam esse aspecto plenamente; entre os demais que também o fazem, apenas um empreendimento possui um desempenho geral modesto.

Adicionalmente, entre os EES de melhor quociente global, nos quais o trabalho se evidencia gratificante e estimulante, verificase de modo quase absoluto a existência de práticas de cooperação no trabalho, de reciprocidade e ajuda mútua e de convivência ou mística grupal. Além disso, a prestação de assistência a membros desfavorecidos do EES, ${ }^{17}$ embora infreqüente (37\%) no cômputo geral, é observável como prática corrente em $58 \%$ dos EES onde o ambiente de trabalho é bastante gratificante e em $78 \%$ dos EES mais bem posicionados, revelando uma provável dupla causalidade: a atenção às pessoas gera disposição para o trabalho que, sendo gratificante, torna natural o cuidado com os colegas. Ao mesmo tempo, constata-se que nesses EES a admissão de sócios atém-se aos princípios cooperativos, além das competências profissionais. Essas características formam um todo sinérgico, no qual a entreajuda, o espírito fraterno e a satisfação, durante e após a atividade propriamente laboral, reforçam-se mutuamente, contribuindo para a obtenção de benefícios e a consolidação do empreendimento. 
Assim, o êxito dos empreendimentos resulta de circunstâncias e fatores cujo efeito positivo decorre proporcionalmente do caráter socialmente cooperativo por eles incorporado. O fator trabalho é passível de ser levado ao seu pleno rendimento como trabalho associado, à medida que se configura uma racionalidade que aproxima e solda os interesses pessoais com os interesses e necessidades coletivas, alinhando a satisfação de ambos a curto e longo prazo e estabelecendo mecanismos duráveis de reciprocidade. Essa relação entre cooperação e eficiência está contida numa formulação seminal para os estudos de economia solidária, quanto à origem da força econômica dessas organizações:

no fato de que um elemento comunitário, de ação e gestão conjunta, cooperativa e solidária, apresente no interior dessas unidades econômicas efeitos tangíveis e concretos sobre o resultado da operação econômica. Efeitos concretos e específicos nos quais se possa discernir uma particular produtividade, dada pela presença e crescimento do referido elemento comunitário, análoga à produtividade que o distingue e pela qual se reconhecem os demais fatores econômicos. (...) Em síntese, o "fator C" significa que a formação de um grupo, associação ou comunidade, que opera cooperativa e cordialmente, proporciona um conjunto de benefícios a cada integrante e um melhor rendimento e eficiência à unidade econômica como um todo, devido a uma série de economias de escala, economias de associação e externalidades, implicadas na ação comunal e comunitária. (Razeto, 1993, p. 40-41)

A racionalidade em questão não significa um retrocesso a formas arcaicas de produção econômica, a menos que se entenda o esvaziamento dos vínculos sociais como uma premissa inexorável da evolução humana. Embora os seus formatos jurídicos e os graus de inovação nos conteúdos de suas relações sociais de produção sejam variáveis e sujeitos à reversão, as práticas de autogestão e cooperação dão a esses empreendimentos uma natureza singular, já ao modificarem o princípio e a finalidade da extração do trabalho excedente. Estando o controle do empreendimento e o poder de decisão em mãos da sociedade de trabalhadores, a gestão do 
empreendimento a ela pertence, cabendo-lhe organizar o processo produtivo, operar as estratégias econômicas e dispor sobre o destinação dos excedentes.

Embora incompleta e sujeita a abalos, a convergência entre interesses individuais e coletivos permite que o empreendimento se conduza simultaneamente por altruísmo recíproco e pelos interesses pessoais de cada trabalhador, individuais e ao mesmo tempo referidos ao grupo, ou à comunidade de trabalho que então se estabelece. A expressão significa que os indivíduos, a partir da vivência e por conta dos objetivos que os unem no trabalho, tecem laços que ultrapassam a esfera material e as satisfações imediatas, à medida que alimentam uma identidade e um projeto comuns, ancorados na história e no espaço por eles partilhados. ${ }^{18}$ As pessoas se reconhecem como integrantes de um coletivo de que são os principais elementos constituintes e para cujo destino concorrem suas decisões e ações, entre elas a forma como acionam a sua capacidade de trabalho.

\section{Superações e paradoxos}

As evidências empíricas aqui expostas referendam alguns dos estudos sobre os efeitos positivos, mesmo quando limitados, da participação dos trabalhadores em cooperativas (Estrin; Jones; Svejnar, 1987; Defourny, 1988), em empresas de autogestão (Peixoto; Lopes, 1999), em fábricas recuperadas pelos trabalhadores (Novaes, 2005) e em empresas socializadas pelo Estado (Espinoza; Zimbalist, 1984). Esse último trabalho possui um interesse particular. Constitui um estudo comparado, amplo e minucioso, de 35 empresas entregues aos trabalhadores pelo governo Allende. Cotejando seus dados com vasta literatura sobre o tema, conclui que há uma relação nitidamente positiva entre participação e produtividade, com destaque para a maior eficácia das novas formas de controle social, exercidas pelos trabalhadores, e para os efeitos das retribuições e estímulos coletivos sobre a inovação gerencial e produtiva (Espinoza; Zimbalist, 1984, p. 163-234). Além disso, constata a influência do contexto nacional 
da época, dado o projeto da Unidade Popular e as políticas setoriais condizentes com sua orientação socialista. Enquanto perdurou uma conjuntura política e econômica globalmente favorável, as empresas de trabalhadores evidenciaram com maior nitidez o seu potencial econômico e social, fato ainda não experimentado no Brasil.

No que lhes diz respeito, as virtualidades contidas na forma social peculiar aos empreendimentos solidários dependem do grau com que introduzem novas relações sociais de produção, distintas das assalariadas. Desse ângulo de compreensão teórica, o nítido polimorfismo das diversas iniciativas populares incluídas no rol da economia solidária não impede que se opere uma redução das mesmas aos seus traços essenciais, para identificar a estrutura interna de suas relações constituintes, posto que nessas reside a sua lógica específica de desenvolvimento, ou sua racionalidade própria. Isto posto, a aplicação desse suporte interpretativo às manifestações concretas da economia solidária requer não somente a consideração das suas respectivas singularidades individuais, mas a percepção daquelas características mais gerais, definidoras do que os empreendimentos representam para a vida econômica dos trabalhadores que a elas acorrem.

A função que os empreendimentos desempenham, em relação ao atendimento de necessidades dos seus integrantes e em relação a aspirações que possuam, parece ser o elemento determinante da forma de organização adotada, da densidade dos seus vínculos solidários e da intensidade com que tais vínculos produzirão os efeitos agregados acima discutidos. As formas autogestionárias e cooperativas mais densas contêm em maior grau aqueles elementos que acionam o círculo virtuoso do trabalho associado, ao mesmo tempo que experimentam com maior nitidez os impasses trazidos dialeticamente pela nova totalidade em que se encontram constituídos. Na extremidade a maior do gradiente, estão as empresas autogestionárias baseadas na socialização integral dos meios de produção e em processos coletivos de trabalho, deliberados democraticamente. Sejam empresas industriais ou cooperativas agropecuárias, comportam os níveis mais elevados de autogestão 
e cooperação, exercidos por empreendimentos que assumem, via de regra, um caráter essencial e dificilmente reversível para os trabalhadores (Gaiger, 2004, p. 385).

Por seu turno, nas cooperativas de trabalho assevera-se mais fácil conciliar os interesses e ganhos individuais - ambos, por sua natureza, geralmente variáveis - com os imperativos de preservação do capital da empresa, de modo a resguardá-la de situações de insolvência, incomum nesse segmento. O preço, no entanto, é a fragilidade do vínculo associativo e, por conseguinte, menor adesão ao coletivo e menor expectativa de condutas altruístas. ${ }^{19}$ A eficiência volta-se contra o solidarismo. Conforme nossos dados, esse custo é atenuado quando o empreendimento possui enraizamento social, dado pela origem popular das suas lideranças e do seu quadro de sócios fundadores, quando os mesmos mantêm relativa homogeneidade socioprofissional e trabalham de forma coletiva. Os vínculos sociais de origem, se cultivados nas interações entre os trabalhadores, resultam em proveito da identidade cooperativa.

Algumas cooperativas de produção agropecuária investigadas indicaram um problema encontrado com certa freqüência nos coletivos de assentamentos: o abandono de muitos associados é justificado pelo fato de que a cooperativa funciona mais ou menos como uma empresa, de modo que alguns, não aceitando essa rigidez, preferem trabalhar sozinhos, deixando-a. A rebeldia se dá contra a imposição de padrões quanto à jornada de trabalho e contra a divisão em setores de produção e funções, que separam as tarefas diretamente produtivas das administrativas. Nesse caso, as preferências individuais se vêem tolhidas pelas necessidades da organização do trabalho e, mais que isso, pela escolha deliberada de um formato produtivo que, contraditoriamente, introduz ao mesmo tempo maior cooperação e maior divisão técnica do trabalho.

Em cooperativas industriais de pequeno porte, uma divisão cooperativa harmoniosa do trabalho vem a predominar, desta feita entre trabalhadores cuja referência não é a polivalência do agricultor familiar, mas a exploração intensiva típica das empresas privadas 
de baixa tecnologia. O problema torna-se naturalmente mais agudo quando o empreendimento faz frente a uma cultura do trabalho legada e a maior complexidade do processo produtivo, o que pressiona pela preservação ou incorporação de estruturas verticais e da hierarquia gerencial e administrativa. Então, apresenta-se o problema do justo equilíbrio entre gerar, preservar e distribuir o excedente, ou mesmo abrir mão de sua otimização, em nome do bem-estar dos trabalhadores. A necessidade imperiosa de produzir a maior quantidade de bens, numa situação de tudo ou nada que ameaça a sobrevivência do empreendimento, reintroduz sub-repticiamente a dialética negativa capital-trabalho e sacrifica, de modo paradoxal, a dimensão humana dos empreendimentos solidários.

Estamos lutando sem trégua - essa afirmação repetida exprime a sina de quem não contou em sua vida com outra providência senão a sua capacidade laboriosa e a sua força de vontade, a mesma que volta a acionar, desta vez com outros companheiros de infortúnio, para quem não se oferece a liberação do trabalho, mas unicamente a via da emancipação pelo trabalho. Com a vantagem que agora encontram-se rompidos pontos cruciais de drenagem da riqueza produzida pelo trabalho, pelos quais se esvai igualmente o seu sentido. As determinações da mercadoria não desapareceram, pois ainda se interpõem e compelem os empreendimentos solidários a uma série de requisitos produtivos; na ausência de externalidades políticas que compensem os ditames do mercado, o ciclo do capital se completa longe do alcance dos produtores diretos, retornando para eles apenas parcialmente. Ainda assim, o trabalho perde em seu caráter abstrato e reificado, e ganha em suas possibilidades de converter-se em prática transformadora da natureza e dos sujeitos.

Seguindo as lições da experiência mantida sob seu domínio, o trabalhador associado percebe que já não ficaria mais pobre à medida que produz mais riqueza e que sua capacidade produtiva cresce em força e extensão. Esboroam-se os círculos reiterativos da alienação: o produto não se opõe ao trabalhador como dantes, quando o comandava como força independente, como se lhe coubesse o lugar do criador; o trabalhador já não está apartado do resultado do 
seu trabalho, que passa a ver como seu; tampouco segue alheio a si próprio, alienado a uma força sua e, não obstante, instrumento do seu jugo. A experiência da autogestão e da cooperação no trabalho dá curso à reflexidade crítica dos indivíduos, ensejando um processo de subjetivação auto-referenciada, no qual ganham sentido e corpo outras identidades e outros horizontes éticos. Uma operação vital, no contexto atual de urgência de novas experimentações, dotadas de uma razão projetiva que as impulsione a seguir insistindo em humanizar a civilização.

\section{Notas}

1 Para uma visão dos diversos enfoques, sugere-se consultar números temáticos de algumas revistas: Sociedade e Estado, v. 16, n. 1/2, jan./ dez. 2001; Ciências Sociais, Unisinos, v. 37, n. 159, jul./dez. 2001; Économie et Solidarités - Revue du CIRIEC, Canadá, número especial, 2003.

2 O dispositivo analítico examina os empreendimentos sob quatro dimensões - autogestão, cooperação, eficiência e viabilidade desdobradas em 60 indicadores. Detalhes da pesquisa e sobre cada um dos empreendimentos encontram-se em: www.ecosol.org.br.

3 Nesse quesito, os critérios de seleção dos casos foram os seguintes: a) avanço efetivo, na auto-sustentação econômica e financeira; b) organização e funcionamento democrático, autogestionário e autônomo, isto é, independente de pessoas ou de órgãos externos de apoio; c) realizações no plano educativo, gerando envolvimento com a comunidade e com questões sociais, além de oportunizar formação profissional; d) relevância econômica para os seus membros, não constituindo-se apenas em uma atividade ocasional, destinada a gerar renda complementar e acessória; e) longevidade: empreendimentos com três anos ou mais (em 1997) de existência.

4 Utilizaremos a sigla EES, para Empreendimentos Econômicos Solidários, quando nos referirmos às 32 experiências pesquisadas. Os EES de triagem de resíduos sólidos são mais conhecidos como associações de reciclagem. 
5 A gestão democrática refere-se à participação livre e igualitária dos membros do empreendimento nas decisões fundamentais, de caráter político, estratégico e administrativo. A autogestão produtiva implica o uso dos mesmos princípios na organização e gerência do processo produtivo, ensejando níveis diferenciados de socialização dos meios de produção e de coletivização do trabalho.

6 Um exemplo ainda, à contramão: em vários assentamentos, a conciliação entre as necessidades de trabalho para o coletivo e a produção familiar foi motivo de tensões, havendo levado o Movimento dos Trabalhadores Rurais Sem Terra a rever sua política de sobrepor peremptoriamente as cooperativas de produção agropecuária aos interesses e às alternativas de produção familiares ou semi-associativas. Um estudo de caso esclarecedor encontra-se em Anjos (2005).

7 Em linguagem mais conceitual, pode-se dizer que o trabalho vivo, diretamente realizado pelos empreendedores, prevalece sobre o trabalho morto, incorporado antecipadamente nas matérias-primas e nos meios de produção.

8 A correta análise dessa questão implica ter consciência do parâmetro de comparação que se deve utilizar, considerando-se a categoria de trabalhadores concretamente em questão, e não simplesmente cotejar as condições de trabalho propiciadas pelos empreendimentos com a situação ideal de relações assalariadas consignadas em carteira, diante de patrões que honrariam os direitos sociais e trabalhistas de seus empregados. Recair em tal idealização, além de quase nada mais representar que uma quimera, para trabalhadores encerrados e escolados na informalidade e na precariedade desde sua entrada no mercado de trabalho (Nunes, 2001), significa abstrair completamente a natureza exploratória das relações sociais de produção capitalistas, antagônicas àquelas perseguidas pelos formatos autogestionários.

9 Convém não obstante lembrar que a natureza não capitalista de uma organização econômica não se mede com segurança pelo caráter coletivo do seu sistema de propriedade. Sistemas individualizados ou semicoletivos de distribuição e uso dos meios de produção podem conter menor grau de concentração do poder, de controle do trabalho e de exploração, que sistemas inteiramente coletivos de propriedade, bastando que nesses se camuflem e se perpetuem formas de divisão social do trabalho. No que respeita à pesquisa, o comportamento do indicador correspondente $(\mathrm{Cl}$ - propriedade coletiva dos principais 
meios de produção) demonstra que a propriedade coletiva não é um pressuposto básico ou uma garantia de que haja implicação similar dos indivíduos e, com isso, melhores resultados. A chave parece residir no grau de cooperação na gestão e nas atividades produtivas do empreendimento, ainda que estejam apoiadas em bens de produção e em economias basicamente individualizadas.

10 No sentido de tensões entre exigências parcialmente inconciliáveis, diante das quais é impossível tanto a mera supressão de um dos termos quanto o estabelecimento definitivo de uma solução intermediária entre ambos.

11 Para um estudo específico desta questão, ver Santos (2004) e Veronese (2005).

12 Ou seja, a adoção de regras coletivizantes seria buscada até o ponto de equilíbrio entre o critério da maior igualdade entre todos e o critério de observância das diferenças de responsabilidade individual - em trabalho, aportes, capacidades. (Cf. John Roemer, apud Arnsperger; Van Parijs, 2000, p. 53).

13 Nesse ponto preciso, coincidimos com um estudo sobre cooperativas de trabalho em Porto Alegre (Piccinini, 2004).

14 O que não quer dizer que os empreendimentos em questão, especialmente as cooperativas de trabalho, sejam indutoras da flexibilização do trabalho, uma questão geralmente mal compreendida. Para o trabalhador, o problema não é tanto a variabilidade da sua taxa de ocupação, pois, embora intensificada no cenário mais recente da economia, ela é característica de inúmeros setores, da produção familiar agrícola a todas aquelas onde predomina o trabalho autônomo, o pequeno comércio e as práticas de subcontratação. O problema principal é a precarização do vínculo de trabalho, quesito em que os empreendimentos representam inegavelmente um elemento progressivo, ao estabelecerem um ponto de referência ou de fixação do trabalhador, frente ao qual ele não está submetido a um papel passivo, como ocorre no vínculo assalariado (em princípio e à exceção das cooperativas de fachada, que, por isso mesmo, fazem jus a esse nome).

15 Nesse segundo caso, o valor percebido pelos trabalhadores termina reduzido a uma divisão periódica de sobras líquidas variáveis. Com isso, sem uma estimativa da agregação de valor aos produtos, em cada etapa do processo produtivo, o cálculo a montante da estrutura de custos fica 
prejudicado; reparte-se, literalmente, o que sobra, com ônus corrente para o trabalhador e o risco de se criar uma situação insustentável a médio prazo.

16 No Plano, o ganho de cada associado tem como base o dobro do piso da categoria, ao que se acrescentam as seguintes bonificações: a) tempo de serviço: $+2,5 \%$ /ano; b) qualificação profissional (assiduidade em eventos da cooperativa e busca de cursos particulares): $+10 \%$; c) participação de coordenação de setor de produção ou da diretoria: 10\%; d) presidência: + um salário piso da categoria.

$17 \mathrm{O}$ indicador em questão refere-se ao atendimento prestado voluntariamente, além do previsto nas normas do EES, em socorro a associados que atravessam situações pessoais ou familiares problemáticas, em função de luto, doença, conflitos, etc.

18 Um caso exemplar são as associações de recicladores de Porto Alegre, cuja fundação ocorreu sucessivamente ao assentamento das famílias, como alternativa de renda oferecida pelo poder público junto ao novo local de moradia. Num processo bastante peculiar, a formação dos grupos de trabalho e a construção dos laços de vizinhança e de relacionamento comunitário se sobrepuseram, tornando indissociáveis o trabalho e a convivência social.

19 Daí a deduzir que essas cooperativas, por não apresentarem práticas solidárias expressivas, coerentes com o ideário cooperativista, certamente não o fazem porque servem a outros reais propósitos (Piccinini, 2004, p. 101), vai uma larga distância.

\section{The rationality of productive self managerial formats}

Abstract: The current solidary economy phenomenon reintroduced the debate on comparative advantages of the collective formats of work management and organization. In order to contribute on the subject, through the articulation between the empirical research and the theoretical reflection, this work analyzes the data of a qualitative inquiry on experiences of solidary economy, also diachronically focusing its dynamic factors, by means of the comparison between results of similar previous researches, carried through in past years. By doing so, this paper considers part of the extensive bibliography on the pros and cons of self-management and the cooperation within economic enterprises. The main stream of the developed 
argument recognizes the indispensable role of the motivations, the participation and the cooperation. At the same time, it reviews the efficiency concept, pointing out the presence of rationality in work community, established in circuits of reciprocity of symbolic and projective content, which determine the behaviors and dilute the borders between individual and collective interests.

Key-words: solidary economy, cooperative work, productive rationality.

\section{Referências bibliográficas}

ANJOS, Eliene dos. COPRASUL: entre o idealizado e o vivido: uma análise da prática cooperativista no MST. Dissertação (Mestrado em em Ciências Sociais) - Universidade Federal da Bahia, Salvador, 2005.

ARNSPERGER, Christian; VAN PARIJS, Philippe. Éthique économique et sociale. Paris: La Découverte, 2000.

CARPI, Juan. La economía social en un mundo en transformación. Revista CIRIEC, España, n. 25, p. 83-115, 1997.

CATTANI, Antônio (Org.). A outra economia. Porto Alegre: Ed. da UFRGS, 2003.

DEFOURNY, Jacques. Coopératives de production et entreprises autogérées: une synthèse du débat sur les effets économiques de la participation. Mondes en Développement, v. 16, n. 61, p. 139-153, 1988.

ESPINOZA, Juan; ZIMBALIST, Andrew. Democracia económica: la participación de los trabajadores en la industria chilena: 1970-1973. Ciudad de Mexico: Fondo de Cultura Económica, 1984.

ESTRIN, Saul; JONES, Derek; SVEJNAR, Jan. The productivity effects of worker participation: producer cooperatives in western economies. Journal of Comparative Economics, n. 11, p. 40-61, 1987.

GAIGER, Luiz. Sobrevivência e utopia: os projetos alternativos comunitários no RS. Cadernos CEDOPE, n. 10, 1994. (Série Movimentos Sociais e Cultura).

Empreendimentos solidários: uma alternativa para a economia popular? In: GAIGER, L. (Org.). Formas de combate e 
de resistência à pobreza. São Leopoldo: Ed. UNISINOS, 1996. p. 101-26.

GAIGER, Luiz. Os caminhos da economia solidária no Rio Grande do Sul. In: SINGER, P.; SOUZA, A. (orgs.). A economia solidária no Brasil: a autogestão como resposta ao desemprego. São Paulo: Contexto, 2000. p. 267-286.

. Virtudes do trabalho nos empreendimentos econômicos solidários. Revista Latinoamericana de Estudios del Trabajo, v. 7, n. 13, p. 191-211, 2001.

GAIGER, Luiz (Org.). Sentidos e experiências da economia solidária no Brasil. Porto Alegre: Ed. da UFRGS, 2004.

GAIGER, Luiz et al. A economia solidária no RS: viabilidade e perspectivas. Cadernos CEDOPE, n. 15, 1999. (Série Movimentos Sociais e Cultura).

KOWARICK, Lúcio (Org.). As lutas sociais e a cidade. Rio de Janeiro: Paz e Terra, 1988.

LEITE, Márcia. Novas formas de gestão da mão-de-obra e sistemas participativos: uma tendência à democratização das relações de trabalho? Educação e Sociedade, n. 45, p. 190-210, 1993.

LIMA, Jacob. O trabalho autogestionário em cooperativas de produção; o paradigma revisitado. Revista Brasileira de Ciências Sociais, v. 19, n. 56, p. 45-62, 2004.

MENDELL, Marguerite. La aparición de movimientos sociales internacionales y la economía social y solidaria. Économie et Solidarités, Revue du CIRIEC, Canada, n. especial, p. 19-29, 2003.

NOVAES, Henrique. Para além da apropriação dos meios de produção? $\mathrm{O}$ processo de adaptação sócio-técnica em fábricas recuperadas. Dissertação (Mestrado em Política Científica e Tecnológica) UNICAMP, Campinas (SP), 2005.

NUNES, Christiane. Cooperativas, uma possível transformação identitária para os trabalhadores do setor informal. Sociedade e Estado, Brasília, v. 16, n. 1-2, p. 134-58, 2001.

PEIXOTO, José; LOPES, Vera. A reestruturação produtiva no Brasil e o caso das empresas industriais sob regime de autogestão ou cogestão. Rio de Janeiro: COPPE-UFRJ, 1999. 
PICCININI, Valmíria. Cooperativas de trabalho de Porto Alegre e flexibilização do trabalho. Sociologias, v. 6, n 12, p. 68- 104, 2004.

PONTE Jr., Osmar(Org.). Mudanças no mundo do trabalho: cooperativismo e autogestão. Fortaleza: Expressão, 2000.

RAZETO, Luis. Economia de solidariedade e organização popular. In: GADOTTI, M.; GUTIÉRREZ, F. (Orgs.). Educação comunitária e economia popular. São Paulo: Cortez, 1993. p. 34-58.

ROSENFIELD, Cinara. Autonomia outorgada e apropriação do trabalho. Sociologias, v. 6, n. 12, p. 202-227, 2004.

SANTOS, Aline. Vivendo e pensando o diferente: representações sociais dos trabalhadores nos empreendimentos de economia solidária. Dissertação (Mestrado em Ciências Sociais Aplicadas) - Universidade do Vale do Rio dos Sinos, 2004.

SANTOS, Boaventura de Souza (Org.). Produzir para viver: os caminhos da produção não capitalista. Rio de Janeiro: Civilização Brasileira, 2002.

SINGER, Paul; SOUZA, André (Orgs.). A economia solidária no Brasil: a autogestão como resposta ao desemprego. São Paulo: Contexto, 2000.

VERONESE, Marília. A difícil apropriação dos modos de trabalhar solidários e autogestionários. Trabalho apresentado no XII Congresso Brasileiro de Sociologia (GT 02 - Desenvolvimento, trabalho e gestão), realizado na cidade Belo Horizonte, em 2005. 